\title{
eDify: Enhancing Teaching and Learning Process by Using Video Streaming Server
}

\author{
https://doi.org/10.3991/ijim.v15i11.20245 \\ Raza Hasan $\left.{ }^{(}\right)$, Sellappan Palaniappan, Salman Mahmood \\ Malaysia University of Science and Technology, Selangor, Malaysia \\ raza.hasanepg.must.edu.my \\ Kamal Uddin Sarker \\ University Malaysia Terengganu, Kuala Terengganu, Malaysia \\ Mian Usman Sattar \\ Beaconhouse National University, Lahore, Pakistan \\ Ali Abbas, Vikas Rao Naidu, Puttaswamy Malali Rajegowda
Knowledge Oasis Muscat, Muscat, Sultanate of Oman
}

\begin{abstract}
Nowadays, Higher Education Institutions (HEIs) take advantage of new technologies to facilitate learners' experience away from the traditional style of learning for their learning experience. The blended learning approach is a widely adopted approach used by HEIs to disseminate knowledge to their learners. The HEI approach in Oman provides blended e-learning with a video streaming server in combination with Moodle. Students faced issues accessing the material; also, faculty cannot use the video interactions about their learning experience. This study aims to develop a mobile application, "eDify," to enhance the video streaming server's existing infrastructure. Furthermore, usability analysis of the mobile application with the learning experience of the students. The current study would reveal the variables that are critical to effective technology-based learning of the students. The implications generated through the study would allow the institution involved in the study to effectively implement the variables required for enhanced teaching and learning with the use of a mobile application. The methodology used in the study was an exploratory study combined with a survey as a quantitative method through the mobile application. Principal component analysis and a range of regression analyses are conducted to test the relationships between the independent and the dependent variable, "learning experience." Results suggest that the usability variables positively and significantly affect the learning experience's dependent variable.
\end{abstract}

Keywords-Mobile Applications, Mobile Learning, Mobile Multimedia, Streaming Media, Usability, Video Streaming Server 


\section{Introduction}

Nowadays, mobile phones have been a pivotal part of our everyday activities. Mobile devices tend to drive an opportunity for Mobile Learning (M-Learning) for students in HEIs. M-Learning provides learners with the characteristics of portability to carry, convenience without any difficulty, and interactivity without any restrictions on time and space constraints. On the other hand, HEIs seeking and implementing innovative instruments to provide students with the flexibility of learning by applying digital technology in teaching and learning. This way, the HEIs can cater to the problems caused by the interaction, communication, and engagement where the cohort is relatively large, and fewer learner attention, or feedback mechanism is fewer due to the lecture's time constraint. M-Learning paved its way for flipped classrooms, a pedagogical method where asynchronous video content such as lectures, practiced problems is given to students as homework founded on behaviorist principles. In contrast, activity and problem-solving activities in the classroom, either individual or group based founded upon a constructivist ideology [1]. Therefore, M-Learning, due to its ease of use, availability of content, and accessibility of network, is helping HEIs different solutions for their courses with the use of the latest trends and technologies.

At Middle East College (MEC), the flip teaching pedagogy was implemented in Fall 2015 [2] by the Center of Academic Practices after the pilot run. The flip teaching pedagogy was fully implemented after Fall 2016. To facilitate flip teaching, this work has been done to provide better facilities for increasing participation, increase efficiency, utilize technology, enhance employability, and embrace innovation. Due to the COVID-19 situation, the Ministry of Higher Education Oman (MoHE) declared the year 20/21 as the year of blended learning [3] as most of the HEIs have shifted from conventional way of teaching to blended teaching [4]. MEC was well equipped in advance and did not face any difficulties in adapting to the new norms. The Streaming Server and eDify support the environment, aligning with the blended teaching and learning model [5]. MEC is also having a partnership with Coventry University UK, where they are using Aula as their blended mode of teaching. Aula offers a mobilefirst, interactive, and engaging teaching and learning environment; with eDify, it is benchmarked with Aula as the UK partner university's standards.

The prototype model was used to develop a mobile learning system, "eDify," used at the college. Where Video Streaming Server (VSS) was already implemented in Spring 2015 as an in-house capability to support flipped teaching pedagogy [6][7] [8]. The primary reason for this application's motivation is to use the existing framework for the VSS and provide the facility to the students to use their mobile phones for their learning. Using eDify to flip the classroom is a quick and easy way to deliver videos in and out of the classroom. It can deliver interactive lessons that increase student and teacher engagement. eDify facilitates the use of classroom devices in a collaborative manner and digital curriculum and assessments for learning. Students can access the lessons from the comfort of their own homes and begin learning at their own pace.

This paper's contribution is: (1) Design and implements a mobile learning system using the existing VSS framework to support teaching and learning with ease using 
mobile devices. (2) System evaluation is based on the usability of the mobile learning system with the students' learning experience.

Section 2 presents an overview of related works in mobile learning systems. Section 3 presents the proposed system used to enhance VSS. Section 4 presents the design and development of "eDify" to enhance teaching and learning. Section 5 presents the implementation of eDify using the enhanced framework. Section 6 presents the research model and hypotheses used in the study. Section 7 presents the research methods and instruments undertaken in the study. Section 8 presents results and discussion. Section 9 concludes and proposes future research directions.

\section{$2 \quad$ Related Works}

Mobile learning or M-learning provides a personalized learning experience to the learners, contextualized space for learning, and where learning happens irrespective of temporal or environmental constraints [9]. Learner, instructor, setting, information, and evaluation are the fundamental elements of mobile learning [10] - the pedagogical approach positions the learner at the forefront of the learning experience. The learners' learning experience reflects a larger pedagogical and technological shift reinforcing educational learning goals rather than the format and location where usability and convenience are essential.

HEI's have taken the aid of M-learning to support and enhance the learning experience for their learners. Elkhateeb, Shehab, and El-bakery [11] developed Easy-Edu on the iOS platform and uses collaborative learning. The application provides scenario storytelling, Multiple Choice Questions (MCQs), and course materials. Hasan et al. [12] used a virtual application that helps dental students to learn the procedures. Hasan et al. [8] implemented a streaming server that helps support the flip teaching in computer courses.

Lim[13] presented a mobile-based interactive teaching model to enhance student engagement using Socrative in a Malaysian university. The off-class setting involves pre-class polls, and the in-class setting involves ungraded quizzes, lectures, quick questions, exit tickets, and graded quizzes.

Moreira and Ferreira [14] used Google tools and Lucidchart modeling tools for constructing UML in the Requirements Engineering course. The tool is specific to courses where UML designing is needed but cannot be useful to other courses.

Wen and Zhang [15] implemented a streaming media server to deliver microlectures on mobile and web platforms. Tamhane et al. [16] used mobile learning applications based on Android platforms to enhance students' programming skills in computer courses. Alshalabi, Hamada, and Elleithy [17] implemented an M-learning system using Learning Path Graph (LPG), providing students with the path of studies for students enrolled in computer science and engineering courses.

Prenner, Rotheneder, and Schikuta [18] used visualization techniques to understand algorithms and data structures with the mobile NetLuke mobile environment.

Vinay, Vaseekharan, and Mohamedally [19] used Problem-based learning and gamified approach to teach learners coding concepts with touch-enabled interactive 
maze game. Bostick et al. [20] developed Sortko based on the android platform for learning to sort algorithms. Mbogo, Blake, and Suleman [21] developed a mobile application using the android platform to support novice learners for the concepts of Java programming using a scaffolding framework.

Papadakis, Kalogiannakis, Sifaki, Vidakis [22] found that students react differently in the online learning environments based mainly on their attitudes and skillset. IT competence students tend to use LMS through their mobile phones more often and positively associated with technology use.

Papadakis, Kalogiannakis, Sifaki, and Vidakis [23][24] study the use of LMS in dissenting the knowledge to students. The study found though students use mobile phones to access the LMS but faced difficulties and see LMS as a digital repository rather than a useful e-learning tool. Limitations of Moodle using mobile phones features access based on reliability and usability.

It is apparent from the preceding discussion that mobile learning platforms are commonly used to reinforce, inspire, develop learner's concepts and learning skills. The study shows that different HEIs, based on their requirements and environmental settings, developed them-learning systems to achieve their educational outcomes. They are restricted to either one or two courses, and regional restrictions are also applicable where the system will be used. Some researchers used animation, visualization, gamification, scaffolding, collaborative techniques to enhance students' learning experience. This gives the study's motivation to utilize an m-learning system with the existing VSS; this is used along with the learning management system (LMS) Moodle. Students faced difficulties accessing the media from their mobile phones; proposed eDify increases students' and teachers' engagement and VSS utilization to the fullest Flipped Learning Environment. Usability and convenience are the vital elements of form-learning, and many studies neglected that aspect. In this study, eDif usability will also be investigated for a better learning experience for the students.

\section{Proposed System}

The ability to promote and improve learning and interaction between learner and instructor is the primary prerequisite for the "eDify" framework. For learners, student's progress in the degree plan and their attitudes will be recorded in a videoassisted module. These features can boost the learner engagement in the module and help the teacher track their learning capabilities. eDify uses the existing framework that supports video streaming in an asynchronous mode. Fig. 1 shows the enhanced framework to support eDify. 


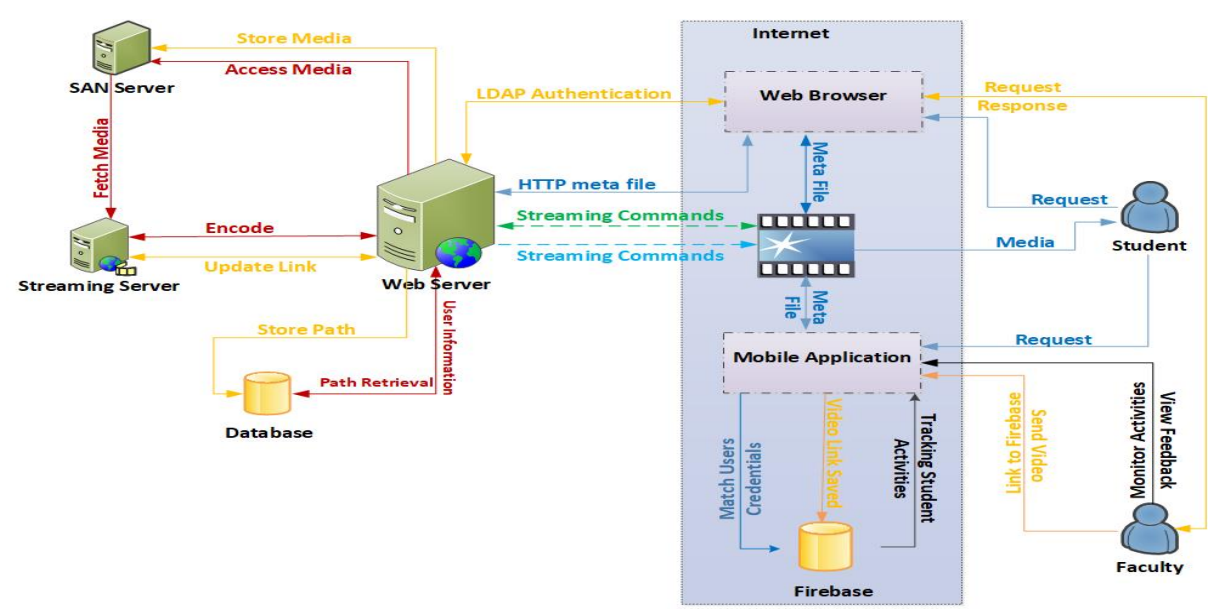

Fig. 1. An enhanced framework to support eDify [8].

The proposed mobile learning platform, called "eDify," is made up of four components: (A) User Infrastructure, (B) Mobile application, (C) Mobile middleware, and (D) Back-end System.

\subsection{User infrastructure}

The VSS Framework supports PCs or Laptops and supports the streaming video via LMS. The enhanced framework supports mobile devices having an Android platform.

\subsection{Mobile application}

eDify is available through Google Play which the user can download with ease. Faculty application, mostly the admin rights and other analysis tools, is shared separately with the designated faculty members. The application allows the faculty to upload the video content through the app or share the existing LMS content. The faculty can create the user id for their specific students within the class and share the password with them. Faculty can also see the feedback given by the students and the video interactions. The searching facility is also provided to search either on a content basis or a specific student id. The student application enables students to see the content and the modules within the application. Here the student has fewer options to like or dislike the content and give feedback about the application and the learning experience.

\subsection{Mobile middleware}

The middleware for the mobile application is utilizing the existing framework that has already been deployed at the premises. Lightweight Directory Access Protocol 
(LDAP) is used for authenticating the users in the web service. The application is being developed on educational, technical, and social dimensions to track its video and student experiences. Using the same college id, faculty must create the login with default " 123456 " as a password which the student can change after the first login.

\subsection{Back-end system}

User authentication in the application is being done using Firebase. The purpose of using Firebase is to provide an authentication mechanism and storing of video interactions done by students, useful for analysis purposes.

\section{Design and Development}

VSS exists, and it is working satisfactorily with LMS. Due to the flip teaching initiative as all the modules must be flipped from Spring 2017. VSS played its role by providing the means to deliver the content and have less bandwidth strain on the LMS [8]. Due to high mobile usage, the students are finding the streaming content difficult to access through the mobile device. To cater this request and problem eDify came to existence, not only it will make the video content used in different modules and is accessible easily but can also store video interactions which can be used later for analysis purpose to enhance the learning process. The first step to choose a name for the application and from different suggestions and options, "edify" was selected as it fits the definition of improving intellectually. The logo's design was done using Adobe illustrator software which serves our requirements.

The development of eDify is done using the Prototyping Model. The reason for choosing this methodology is that requirements were known in advance, and there is no existing system available [25]. Another advantage of using this methodology is that constant feedback was taken during the application's development from students and faculty members. In this methodology, a modification was done at quite an early stage of the application's development. Thus, creating an opportunity to have a quick implementation and fully functional application.

\section{$5 \quad$ Implementation of Proposed System}

As discussed earlier, eDify uses the android platform; Android Studio is used to develop the application. Testing is done using the Samsung J7 Pro device, and a simulator was used in the debugging phase. This is done to test the functionalities and performance of the application. After the successful testing rounds, the application was shared with the stakeholders for implementation. Later the Android Application Package (APK) was uploaded on Google Play from where the users can download it for free from the link (https://play.google.com/store/apps /details?id=com.debugger.Edify\&hl=en_US). Though the application can be downloaded free, it is confined to college students only, and the faculty members can initi- 
ate the registration for their respective modules. The application is split into two portions (i) Student Application, (ii) Admin Application.

\subsection{Student application}

The student application provides features applicable to students only, another option is to provide feedback on the application, and this option is given to the student once. Students can view the modules they are registered by the faculty and view the video content. Additional feature such as Like/Dislike is also provided on each video to improve the interaction purposes and enhances the content-based which can also be used for statistics.

The faculty create a login screen where the student uses their student id and password. After the first successful login, the student must change the password used for later login in the application.

After the successful login, the student can select the modules in which the faculty enroll them, and the student can see the content based on the module code. They can give feedback only once about the application and the learning experience from the application. The input is intended to increase the consistency of the material offered to students and ask about their learning experience. The data is stored about the interactions and the feedback on the Firebase database, which can later be used for analysis purposes. The purpose of making all the modules and content available to students is to increase their systematic and pragmatic knowledge as the videos will not be limited to their course work only.

\subsection{Admin application}

After the administrator's successful login, the home screen appears where the faculty can choose multiple options such as media report, feedback report, view modules, etc. The feedback option reports the statistics on students' feedback about the application and their learning experience.

The media report option provides the video interaction screen where the student interactions' information has been shown on specific video content or can search using the student id. Admin can use the view modules option to see the modules within the application. The view password option is used in case any student forgotten their password and wants to reset it. Add student option is used to create a new student in eDify.

\section{Research Model and Hypothesis}

Designing a mobile learning system needs to consider user satisfaction, limitations, usability, functionality. Usability evaluation methods have to be explicitly studied due to the limitations in developing mobile applications [26]. Usability is one of the essential fundamentals of mobile learning applications and is considered the main challenge in accessing mobile learning evaluation [27]. According to the literature review, 
they considered Learning Experience as an indicator for the model's simplicity. One factor, usability, was chosen to build the hypothesis.

H1: Usability of application will have a positive and significant effect on Learning Experience.

\section{$7 \quad$ Research Method and Instrument}

The study was carried out using an exploratory study and survey technique used as a quantitative method.

\subsection{Module selection}

E-Commerce Technologies (COMP 0382) was chosen as the module for this study because it aims to familiarize the student with the e-commerce-oriented aspects of internet technology. This module is a core module for software specialization and an elective module in computer hardware and networking, multimedia, and business information system. This will allow maximum users required for the study, as shown in section 7.3.

\subsection{Exploratory study}

Exploratory research is carried out to determine the appropriate sample size. A total of 15 students were invited to a focused group. They were asked whether they were willing to use a mobile application for an enhanced learning experience. Nine of them responded positively, while the other six did not. This means that $60 \%$ of them represent the study population who would use the mobile application for learning. The exploratory study was used to generate the items for the dependent variable of 'Learning experience.' To reduce the number of variables from 16 to 5, Principle Component Analysis (PCA) is used. Items generated from the exploratory research regarding the dependent variable were tested through Cronbach's alpha to determine the degree to which they captured the dependent variable, "Learning Experience," for reliability. Regression analyses were carried out to estimate relationships between "Learning Experience" and independent variables for validity.

\subsection{Sampling}

For the primary analysis, the study is going to use Regression Analysis. SPSS is used to determine a suitable sample size. The formula used is as follows:

$$
\begin{gathered}
\text { Sample Size }(\mathrm{n})=\mathrm{p} * \mathrm{q}\left(\frac{Z}{e^{2}}\right) \\
\text { Sample Size }(\mathrm{n})=0.6 * 0.4 *\left(\frac{1.96}{0.05^{2}}\right)
\end{gathered}
$$




$$
\begin{gathered}
\text { Sample Size }(\mathrm{n})=0.6 * 0.4 *\left(\frac{1.96}{0.0025}\right) \\
\text { Sample Size }(n)=024 * 784 \\
\text { Sample Size }(n)=188 \text { approx. }
\end{gathered}
$$

Where $p=$ expected percentage of the response variable, $q=1-p$ (inverse of $p$ ), $Z$ $=$ standard score (1.96 for $95 \%$ confidence level) and $\mathrm{e}=$ accepted margin of error ( 0.05 if the confidence interval is $95 \%$ ).

\subsection{Instrument}

A quantitative method is used with a survey technique. A questionnaire is developed and used for data collection. The questionnaire used in this research consists of 16 variables (refer to Table II). The questions related to the usability of the application and the learning experience of the users were constructed using the usability evaluation model. 5 components were used for this study, namely device efficiency, application usability, user-friendliness, functionality, and accessibility, which were extracted using PCA [28][29]. Q1-Q8 explains the application usability, Q9-Q11 explains the device efficiency, Q12-Q13 explains user-friendliness, Q14-Q15 explains functionality, and Q16 explains mobile media usage. In a non-randomized convenience study, the variables were on a five-point scale ranging from strongly accept to disagree strongly, with the mid-point uncertain. [22]. The study uses a four-point adjectival ordinal scale to measure the responses (Strongly Disagree $=1$, Disagree $=2$, Agree=3, Strongly Agree=4).

\subsection{Data collection}

The data was collected using eDify application. The collected data is stored in Firebase from third-year students enrolled in the sixth semester from March 2019 December 2019. A total of 188 students volunteered to participate in this study, and they used the smartphone app to complete the survey.

\section{Results and Discussion}

Total of 16 variables with regards to the mobile application and the features through PCA. The analysis generated a 5-factor solution with Kaiser-Meyer-Olkin (KMO) of 0.879 and Bartlett's test significance of zero, as shown in Table 1. 
Table 1. KMO and Bartlett's Test

\begin{tabular}{|l|l|c|}
\hline \multicolumn{2}{|c|}{ Kaiser-Meyer-Olkin Measure of Sampling Adequacy. } & .879 \\
\hline \multirow{3}{*}{ Bartlett's Test of Sphericity } & Approx. Chi-Square & 696.468 \\
\cline { 2 - 3 } & Df & 120 \\
\cline { 2 - 3 } & Sig. & .000 \\
\hline
\end{tabular}

The PCA analysis generated a five-factor solution. The table below shows the five factors and their corresponding items, as shown in Table 2.

Table 2. Rotated Matrix of Components

\begin{tabular}{|c|c|c|c|c|c|}
\hline Items & $\begin{array}{c}\text { Application } \\
\text { Usability }\end{array}$ & $\begin{array}{l}\text { Device } \\
\text { Efficiency }\end{array}$ & $\begin{array}{c}\text { User } \\
\text { Friendli- } \\
\text { ness }\end{array}$ & $\begin{array}{c}\text { Func- } \\
\text { tionality }\end{array}$ & \begin{tabular}{|c|c}
$\begin{array}{c}\text { Usage of } \\
\text { mobile } \\
\text { media }\end{array}$ \\
\end{tabular} \\
\hline $\begin{array}{l}\text { Q1: Internet availability is an obstacle to learn- } \\
\text { ing. }\end{array}$ & 0.368 & & & & \\
\hline Q2: Screen size is an obstacle to learning. & 0.58 & & & & \\
\hline $\begin{array}{l}\text { Q3: Appropriate feedback is provided on the } \\
\text { screens within a reasonable time. }\end{array}$ & 0.313 & & & & \\
\hline $\begin{array}{l}\text { Q4: The application follows real-world conven- } \\
\text { tions, making information in a natural and } \\
\text { logical order. }\end{array}$ & 0.642 & & & & \\
\hline $\begin{array}{l}\text { Q5: The Application provides user control and } \\
\text { freedom for navigation. }\end{array}$ & 0.62 & & & & \\
\hline $\begin{array}{l}\text { Q6: Good error prevention mechanism is in } \\
\text { place. }\end{array}$ & 0.692 & & & & \\
\hline $\begin{array}{l}\text { Q7: Application objects, actions, and options } \\
\text { visible, making recognition easy rather than } \\
\text { recall. }\end{array}$ & 0.666 & & & & \\
\hline $\begin{array}{l}\text { Q8: The application is self-explanatory and } \\
\text { easier to use without help or documentation. }\end{array}$ & 0.668 & & & & \\
\hline $\begin{array}{l}\text { Q9: Learning by mobile helps me learn at my } \\
\text { convenience. }\end{array}$ & & 0.766 & & & \\
\hline $\begin{array}{l}\text { Q10: Aesthetic and minimalist design makes it } \\
\text { easier for a user to interact. }\end{array}$ & & 0.625 & & & \\
\hline Q11: Device storage capacity hinders learning. & & 0.521 & & & \\
\hline $\begin{array}{l}\text { Q12: Learning by mobile increases my motiva- } \\
\text { tion for learning and in an unconventional } \\
\text { manner. }\end{array}$ & & & 0.79 & & \\
\hline $\begin{array}{l}\text { Q13: Error messages are expressed in simple } \\
\text { and straightforward language, avoiding codes. }\end{array}$ & & & 0.533 & & \\
\hline $\begin{array}{l}\text { Q14: Having media files of my course content } \\
\text { on my mobile helps me enhance my } \\
\text { knowledge. }\end{array}$ & & & & 0.52 & \\
\hline $\begin{array}{l}\text { Q15: Charging devices regularly is an obstacle } \\
\text { to learning. }\end{array}$ & & & & 0.823 & \\
\hline $\begin{array}{l}\text { Q16: The use of mobile media applications } \\
\text { helps in educational attainment. }\end{array}$ & & & & & 0.914 \\
\hline
\end{tabular}

Extraction Method: Principal Component Analysis. - Rotation Method: Varimax with Kaiser Normalization $^{\mathrm{a}}$

a. Rotation converged in 10 iterations. 
A regression analysis based on the five independent variables of Application usability, Device efficiency, User-friendliness, Functionalities, and Usage of mobile media and the dependent variable of Learning Experience was conducted. The result suggested that the independent variable explains around $89 \%$ of the variability. Hence, the learning experience is significant because of the $p$-value of zero, as shown in Table 3.

Table 3. Variables Entered/Removed

\begin{tabular}{|c|l|l|l|}
\hline Model & \multicolumn{1}{|c|}{ Variables Entered } & Variables Removed & \multicolumn{1}{c|}{ Method } \\
\hline 1 & $\begin{array}{l}\text { Usage of mobile media, Functionalities, User-friendliness, } \\
\text { Device efficiency Application usability }\end{array}$ & Learning Experience & Enter \\
\hline
\end{tabular}

a. Dependent Variable: Learning Experience, b. All requested variables entered.

The results in Table 4 suggest that the independent variable explains around $89 \%$ of the variability.

Table 4. Model Summary

\begin{tabular}{|c|c|c|c|c|}
\hline Model & R & R Square & Adjusted R Square & Std. Error of the Estimate \\
\hline 1 & $.944^{\mathrm{a}}$ & .890 & .887 & .12791 \\
\hline
\end{tabular}

a. Predictors: (Constant), mobile media usage, Functionalities, User-friendliness, Device efficiency, Application usability.

The analysis of variance (ANOVA) above in Table 5 clearly shows that the model is feasible as the significance is zero with an $\mathrm{F}$ value of 269.6.

Table 5. ANOVA

\begin{tabular}{|c|l|c|c|c|c|c|}
\hline \multicolumn{2}{|c|}{ Model } & $\begin{array}{c}\text { Sum of } \\
\text { Squares }\end{array}$ & df & Mean Square & F & Sig. \\
\hline \multirow{3}{*}{1} & Regression & 22.061 & 5 & 4.412 & 269.671 & $.000^{\mathrm{b}}$ \\
\cline { 2 - 7 } & Residual & 2.716 & 166 & .016 & & \\
\cline { 2 - 7 } & Total & 24.777 & 171 & & & \\
\hline
\end{tabular}

a. Dependent Variable: Learning Experience, b. Predictors: (Constant), mobile media usage, Functionalities, User-friendliness, Device efficiency, Application usability.

The independent variables all significantly and positively influence the dependent variable of 'Learning Experience' as all $\mathrm{p}$ values are ' 0 ' and all coefficients are positive Table 6.

One standard deviation improvement is a $17.3 \%$ increase in the learning experience [30]. This is because the ease of usability of the application enhances the Learning Experience as the students use more of the user-friendly application to gain knowledge. For device efficiency, the dependent variable or the learning experience will improve by $24 \%$ if there is an improvement of 1 standard deviation in the device's efficiency [31]. Due to the increase of mobile culture, students are more dependent on the devices. Hence, the devices' efficiency plays a vital role in engaging the students with the application for a better learning experience. The learning experi- 
ence will change by $35.3 \%$ if there is an enhancement in the mobile phone's functionalities [32][33]. With improved application functionalities, the students are more likely to respond positively to their motivation for learning. User-friendliness has a positive and significant impact on Learning Experience [34]. Hence, one standard deviation change in user-friendliness could result in a $25.5 \%$ change in the students' learning experience. The conventions used within the application helps students to identify the working of the application quickly. Hence, conventions enable them to navigate easily within the application. Usage of mobile media is a critical factor as one standard deviation improvement will lead to a $47 \%$ increase in the students learning experience [35]. Faster network speeds and more storage capacity significantly play an essential role in utilizing the device and the application.

Table 6. Coefficients

\begin{tabular}{|c|c|c|c|c|c|c|}
\hline & \multirow{2}{*}{ Model } & \multicolumn{2}{|c|}{ Unstandardized Coefficients } & \multirow{2}{*}{\begin{tabular}{|c|}
$\begin{array}{c}\text { Standardized } \\
\text { Coefficients }\end{array}$ \\
Beta \\
\end{tabular}} & \multirow[t]{2}{*}{$\mathbf{T}$} & \multirow[t]{2}{*}{ Sig. } \\
\hline & & $B$ & Std. Error & & & \\
\hline \multirow{6}{*}{1} & (Constant) & .107 & .106 & & 1.006 & .316 \\
\hline & Application usability & .142 & .028 & .173 & 5.096 & .000 \\
\hline & Device efficiency & .184 & .024 & .240 & 7.566 & .000 \\
\hline & User-friendliness & .208 & .025 & .255 & 8.401 & .000 \\
\hline & Functionalities & .227 & .018 & .353 & 12.763 & .000 \\
\hline & Usage of mobile media & .216 & .012 & .470 & 17.914 & .000 \\
\hline
\end{tabular}

a. Dependent Variable: Learning Experience

To improve the learning experience, application usability is essential as it results in overall satisfaction. Faculty inputs are vital in making the environment conducive to learning as these inputs would improve the overall usability of the systems used by HEIs. Device efficiency impacts these days as most of the new mobile devices have enough storage capacity inbuilt, and the system uses the asynchronous mode of transmission, which does not consume storage memory on the device. The network infrastructure and internet speed depend on the media running of streaming media smoothly. Real-world conventions usage helps the user navigate the system efficiently and relates to social media, where the Like/Dislike option makes students feel content about the media shared with them. Furthermore, students seem quite enthusiastic about giving feedback on the media. Though innovation can be useful for learning, student's usage of a mobile device has increased, resulting in the reduction of the device battery consumption and their constant utilization of network bandwidth.

\section{Conclusion and Future Works}

Developing a mobile learning environment to enhance the teaching and learning process always poses a challenge to HEIs regarding what setting will benefit the stakeholders. In this paper, a mobile learning application named "eDify" has been developed and implemented using the existing infrastructure. The mobile application 
extends the existing video streaming server to support a blended learning approach, improving the learners' ability to interact with the teaching material with ease that they face while accessing moodle from their mobile devices. The proposed application was implemented at Middle East College's computing department, and evaluation of the usability of the application with the learning experience was done by sixthsemester students enrolled in the module E-Commerce Technologies (COMP 0382).

To test the research question, survey techniques were used through the mobile application comprising 16 questions. Kaiser-Meyer-Olkin (KMO) of 0.879 indicates the sampling for the undertaken study is adequate. Bartlett's test significance of zero indicates factor analysis may be useful. PCA is undertaken to reduce the number of variables and came to 5 factors, namely Application usability, Device efficiency, Userfriendliness, Functionalities, Usage of mobile media. The advantage of using PCA is that it comprises both exploratory and confirmatory analysis together. Regression analyses were carried out to estimate relationships between "Learning Experience" and independent variables for validity. Analysis of variance using ANOVA was done to study the associated estimation procedures.

To answer the research question, "Usability of application will positively and significantly affect Learning Experience." Results suggest that the independent variables relating to the application's usability positively and significantly influence the learning experience. Consequently, the null hypothesis is rejected in favor of the alternative hypothesis: the application's usability will positively and significantly affect the learning experience. As mobile culture is on the rise in academic institutions and students always look for easy-to-use applications with maximum facilities or functionalities and efficiency plays a vital role in the students' learning experience. However, the study found that mobile media usage has a $47 \%$ increase in the students' learning experience, which is in terms of storage not having an issue.

In addition to the reported findings, the study has some limitations. Firstly, the study can be conducted on another different module with a more significant cohort. Secondly, data security and data privacy can be imposed as access can be used by all the stakeholders such as students, faculty, and management. Thirdly, crossdepartment and cross-institutional studies can be done better to analyze the findings' components and accuracy. Lastly, studies can be done based on multidisciplinary effects and more significant samples. A critical study should be undertaken to determine the moderating or mediating effects of certain variables such as technologybased learning culture, staff support, video interactions, a wide range of institutions, and linguistics on the students' learning experience.

At present, the video interaction can let the faculty know about the module's learners' behavior patterns. For the future, these patterns can help predict the student's success, retention, and early dropout within the module.

For the future, a comprehensive dashboard revealing these patterns coming from the different e-learning environments applied at the HEI can be made visible to students and management. This will help faculty find the learners' overall and individual performance, self-monitor their progress within the module, and make a better decision in their teaching and learning strategies for the future. Video learning analytics can play a vital role in extending student experience where a blended learning ap- 
proach is applied. This can also lead institutions to adapt to a fast-changing world where different ways are used to disseminate knowledge to the learners [36] [37] [38] [39] [40] [41] [42] [43].

\section{Acknowledgement}

The exploratory study was conducted at the Department of Computing at Middle East College, Oman. The author like to thank the Head of the Department for providing support and encouragement.

\section{References}

[1] J. L. Bishop and M. A. Verleger, "The flipped classroom: A survey of the research," 2013.

[2] D. Bino, K. G. Rajalakshmi, and C. Ramaiah, "An Iterative Approach for Institutional Adoption and Implementation of Flipped Learning: A Case Study of Middle East College," 2018, doi: $10.1007 / 978-3-319-73210-7 \quad 63$.

[3] L. Kothaneth, "E-learning is here to stay," Oman Observer, p. 1, 2020.

[4] M. Drolia, E. Sifaki, S. Papadakis, and M. Kalogiannakis, "An Overview of Mobile Learning for Refugee Students: Juxtaposing Refugee Needs with Mobile Applications' Characteristics," Challenges, 2020, https://doi.org/10.3390/challe11020031

[5] K. K. Poloju and V. R. Naidu, "Impact of E-tools in Teaching and Learning for Undergraduate Students," in Lecture Notes in Networks and Systems, 2020, pp. 783-790.

[6] R. Hasan, S. I. Ali, and M. S. Hayat, "Enhancing student's learning experience at middle east college by using blended learning," in Proceedings of the 2015 Science and Information Conference, SAI 2015, 2015, pp. 797-800, https://doi.org/10.1109 /sai.2015.7237235

[7] R. Hasan, S. Palaniappan, A. R. A. Raziff, S. Mahmood, and K. U. Sarker, "Student Academic Performance Prediction by using Decision Tree Algorithm," in 2018 4th International Conference on Computer and Information Sciences: Revolutionising Digital Landscape for Sustainable Smart Society, ICCOINS 2018 - Proceedings, Aug. 2018, pp. 1-5, https://doi.org/10.1109/iccoins.2018.8510600

[8] R. Hasan, S. Palaniappan, S. Mahmood, B. Shah, A. Abbas, and K. U. Sarker, "Enhancing the teaching and learning process using video streaming servers and forecasting techniques," Sustain., vol. 11, no. 7, p. 2049, Apr. 2019, https://doi.org/10.3390/su11072049

[9] H. Crompton, "A historical overview of m-learning: Toward learner-centered education," Handb. Mob. Learn., 2013.

[10] F. Ozdamli and N. Cavus, "Basic elements and characteristics of mobile learning," 2011, doi: $10.1016 /$ j.sbspro.2011.11.173.

[11] M. Elkhateeb, A. Shehab, and H. El-bakery, "Mobile Learning System for Egyptian Higher Education Using Agile-Based Approach," Educ. Res. Int., vol. 2019, pp. 1-13, Mar. 2019, https://doi.org/10.1155/2019/7531980

[12] R. Hasan, M. Ghufran, S. S. Javed, Hammad-Ul-Haq, A. Azeem, and D. Jamil, "SMART virtual dental learning environment," in 2019 4th MEC International Conference on Big Data and Smart City, ICBDSC 2019, 2019, pp. 1-4, https://doi.org/10.1109 /icbdsc.2019.8645584 
[13] W. N. Lim, "Improving student engagement in higher education through mobile-based interactive teaching model using socrative," 2017, https://doi.org/10.1109/educon.2017. $\underline{7942879}$

[14] F. Moreira and M. J. Ferreira, "Teaching and learning requirements engineering based on mobile devices and cloud: A case study," in Blended Learning: Concepts, Methodologies, Tools, and Applications, 2016. https://doi.org/10.4018/978-1-5225-0783-3.ch059

[15] C. Wen and J. Zhang, "Design of a Micro lecture Mobile Learning System Based on Smartphone and Web Platforms," IEEE Trans. Educ., 2015, doi: $\underline{10.1109 / \text { TE.2014.2363627. }}$

[16] K. Tamhane, W. T. Khan, S. R. Tribhuwan, A. P. Burke, and S. B. Take, "Mobile Learning Application,” Int. J. Sci. Res. Publ., 2015.

[17] I. A. Alshalabi, S. Hamada, and K. Elleithy, "Automated adaptive learning using smart shortest path algorithm for course units," 2015, https://doi.org/10.1109/lisat.2015.7160187

[18] G. Prenner, A. Rotheneder, and E. Schikuta, "NetLuke: Web-based teaching of algorithm and data structure concepts harnessing mobile environments," 2014, https://doi.org/10.1145/2684200.2684292

[19] S. Vinay, M. Vaseekharan, and D. Mohamedally, "RoboRun: A gamification approach to control flow learning for young students with TouchDevelop," arXiv Prepr. arXiv1310.0810, 2013.

[20] I. Boticki, A. Barisic, S. Martin, and N. Drljevic, "Teaching and learning computer science sorting algorithms with mobile devices: A case study," Comput. Appl. Eng. Educ., 2013, https://doi.org/10.1002/cae.21561

[21] C. Mbogo, E. Blake, and H. Suleman, "A mobile scaffolding application to support novice learners of computer programming,” 2013, https://doi.org/10.1145/2517899.2517941

[22] S. Papadakis, M. Kalogiannakis, E. Sifaki, and N. Vidakis, "Evaluating Moodle use via Smart Mobile Phones. A case study in a Greek University," EAI Endorsed Trans. Creat. Technol., 2018, https://doi.org/10.4108/eai.10-4-2018.156382

[23] S. Papadakis, M. Kalogiannakis, E. Sifaki, and N. Vidakis, "Access Moodle Using Smart Mobile Phones. A Case Study in a Greek University," in Lecture Notes of the Institute for Computer Sciences, Social-Informatics and Telecommunications Engineering, LNICST, 2018, pp. 376-385.https://doi.org/10.1007/978-3-319-76908-0 36

[24] S. Papadakis, "Tools for evaluating educational apps for young children: a systematic review of the literature," Interact. Technol. Smart Educ., 2020, https://doi.org/10.1108/itse$\underline{08-2020-0127}$

[25] B. Bähr, "Towards a requirement catalogue for prototyping tools of mobile user interfaces," 2015, doi: 10.1007/978-3-319-20898-5 48.

[26] Jakob Nielsen and Raluca Budiu, Mobile Usability, 1st ed. New Riders, 2012.

[27] G. Vavoula and M. Sharples, "Meeting the Challenges in Evaluating Mobile Learning: A 3-Level Evaluation Framework," Int. J. Mob. Blended Learn., 2009, https://doi.org/10.4018/jmbl.2009040104

[28] A. Hussain and A. M. Omar, "Usability evaluation model for mobile visually impaired applications," Int. J. Interact. Mob. Technol., 2020, https://doi.org/10.3991 /ijim.v14i05.13349

[29] S. Papadakis, J. Vaiopoulou, M. Kalogiannakis, and D. Stamovlasis, "Developing and exploring an evaluation tool for educational apps (ETEA) targeting kindergarten children," Sustain., 2020, https://doi.org/10.3390/su12104201

[30] W. Coutinho, E. Couto, C. Biase, P. Fernandes, and B. Bonifacio, "Improving an Educational Mobile Application Through Usability Evaluation," Inted2015 9Th Int. Technol. Educ. Dev. Conf., 2015. 
[31] I. García-Martínez, J. M. Fernández-Batanero, D. C. Sanchez, and A. L. de la Rosa, "Using mobile devices for improving learning outcomes and teachers' professionalization," Sustainability (Switzerland). 2019, https://doi.org/10.3390/su11246917

[32] S. Roohullah Jan, F. Ullah, H. Ali, and F. Khan, "Enhanced and Effective Learning through Mobile Learning an Insight into Students Perception of Mobile Learning at University Level,” Int. J. Sci. Res. Sci. Eng. Technol., 2016.

[33] S. Al Hosni, "Mobile Learning: Enhancing Learning Through Cell Phones," BEST Int. J. Manag. Inf. Technol. Eng., 2016.

[34] J. Kapenieks, "User-friendly e-learning environment for educational action research," Procedia Comput. Sci., 2013, https://doi.org/10.1016/j.procs.2013.12.012

[35] M. Bikanga Ada, M. Stansfield, and G. Baxter, "Using mobile learning and social media to enhance learner feedback: Some empirical evidence,” J. Appl. Res. High. Educ., 2017, https://doi.org/10.1108/jarhe-07-2015-0060

[36] R. Hasan, S. Palaniappan, S. Mahmood, A. Abbas, K. U. Sarker, and M. U. Sattar, "Predicting student performance in higher educational institutions using video learning analytics and data mining techniques," Appl. Sci., 2020, https://doi.org/10.3390/app10113894

[37] M. Mustafa, V. R. Naidu, Q. A. Mohammed, K. A. Jesrani, R. Hasan, and G. Al Hadrami, "A Framework for Collaborative and Active Learning for Enhancing Student Engagement," IJAEDU- Int. E-Journal Adv. Educ., 2019, https://doi.org/10.18768/ijaedu.531644

[38] R. Hasan, S. Palaniappan, S. Mahmood, K. U. Sarker, and A. Abbas, "Modelling and predicting student's academic performance using classification data mining techniques," Int. J. Bus. Inf. Syst., vol. 34, no. 3, pp. 403-422, 2020, https://doi.org/10.1504 /ijbis.2020.108649

[39] J. Lester, C. Klein, H. Rangwala, and A. Johri, "Learning Analytics in Higher Education," ASHE High. Educ. Rep., 2017, https://doi.org/10.1002/aehe.20121

[40] S. Mahmood, S. Palaniappan, R. Hasan, K. U. Sarker, A. Abass, and P. M. Rajegowda, "Raspberry PI and role of IoT in Education," in 2019 4th MEC International Conference on Big Data and Smart City (ICBDSC), Jan. 2019, pp. 1-6, https://doi.org/10.1109 /icbdsc.2019.8645598

[41] M. Hayat, R. Hasan, S. Imran Ali, and M. Kaleem, "Active learning and student engagement using Activity Based Learning," in 2017 International Conference on Infocom Technologies and Unmanned Systems: Trends and Future Directions, ICTUS 2017, Dec. 2018, vol. 2018-Janua, pp. 201-204, https://doi.org/10.1109/ictus.2017.8286005

[42] R. Hasan et al., "A Review: Emerging Trends of Big Data in Higher Educational Institutions," in Lecture Notes in Networks and Systems, vol. 106, 2020, pp. 289-297.

[43] M. U. Sattar, S. Palaniappan, A. Lokman, N. Shah, U. Khalid, and R. Hasan, "Motivating medical students using virtual reality-based education," Int. J. Emerg. Technol. Learn., 2020, https://doi.org/10.3991/ijet.v15i02.11394

\section{Authors}

Raza Hasan received his $\mathrm{PhD}$. in Informatics from Malaysia University of Science and Technology. He serves as Senior Lecturer in Computing Department at Middle East College, Muscat, Oman. Email: raza.hasan@pg.must.edu.my

Sellappan Palaniappan is a Professor of IT and Dean of School of Science and Engineering at Malaysia University of Science and Technology. 
Salman Mahmood is a lecturer in the Computer Engineering Department at Sir Syed University of Engineering \& Technology, Karachi, Pakistan.

Kamal Uddin Sarker is a Senior Lecturer in Computing Department at Middle East College, Muscat, Oman.

Ali Abbas is an Assistant Professor in Computing Department at Middle East College, Muscat, Oman.

Mian Usman Sattar is an Assistant Professor in School of Business, Department of Management, Beaconhouse National University, Pakistan.

Vikas Rao Naidu is a Senior Lecturer in Computing Department at Middle East College, Muscat, Oman.

Puttaswamy Malali Rajegowda is a Senior Lecturer in Computing Department at Middle East College, Muscat, Oman.

Article submitted 2020-12-03. Resubmitted 2021-03-11. Final acceptance 2021-03-11. Final version published as submitted by the authors. 